Original article

Section: Food Quality and Functionality

\title{
Enhancement of the Stabilities and Intracellular Antioxidant Activities of Lavender Essential Oil by Metal-Organic Frameworks Based on $\beta$-Cyclodextrin and Potassium Cation
}

\author{
Ying Wang ${ }^{\oplus}$, Liang Wang, Jin Tan ${ }^{\circledR *}$, Rong Li, Zi-Tao Jiang, Shu-Hua Tang \\ Tianjin Key Laboratory of Food Biotechnology, College of Biotechnology and Food Science, \\ Tianjin University of Commerce, Tianjin 300134, China
}

Key words: microcapsulation, thermal stability, pH stability, cell viability, cellular antioxidant model, application extension

Lavender (Lavandula angustifolia) is an important medicinal and aromatic plant. However, the application of lavender essential oil (LEO) is limited by its instability, low solubility and high volatility. Therefore, to improve the stabilities and antioxidant activities of LEO and thereby expand the applications, LEO was microencapsulated by metal-organic frameworks based on $\beta$-cyclodextrin and potassium cation (K- $\beta C D$-MOFs) with different mass core/wall ratios. The results showed that the best inclusion rate was $96.67 \%$ with the ratio of 1:10. Then, the optimum inclusion product was characterized by Fourier transform infrared spectroscopy (FTIR) and scanning electron microscope (SEM). The thermal and pH stabilities and the intracellular antioxidant activities were also studied. The results showed that the stabilities of the oil with K- $\beta C D-M O F s$ inclusions and their abilities to resist acid and alkali were significantly stronger than those of LEO itself. In addition, the intracellular antioxidant activities of LEO were also enhanced by the $\mathrm{K}-\beta \mathrm{CD}-\mathrm{MOF}$ inclusion. These results suggested the potential of K- $\beta C D-M O F s$ as carriers for essential oils in food industry applications.

\section{INTRODUCTION}

Lavender (Lavandula angustifolia), an aromatic plant belonging to the family Lamiaceae, is widely grown for essential oil production due to its aromatic property [Shafaei et al., 2017]. This herbal plant is commonly utilized in many industrial fields including cosmetics, perfumes, pharmaceuticals, and foods [Yuan et al., 2019]. Taking foods as an example, it is widely used as flavoring in beverages, herbal teas, ice creams, sweets, cakes, and other aromatic plant products [Dong et al., 2020]. Essential oil, the most important and popular product of this aromatic plant, mainly exists in the glands of the aerial parts including flowers and leaves [Lis-Balchin, 2002]. The lavender essential oil (LEO) is believed to have anti-depressive, anti-inflammatory, antimicrobial (antibacterial/ antifungal) and antioxidant characteristics [Cavanagh \& Wilkinson, 2005; Insawang et al., 2019; Kwiatkowski et al., 2020]. LEO is also prevalent in the pharmaceutical, cosmetic and food industries. However, the applications of LEO are limited by its highly unstable and volatile properties. As the essential oils are composed of various volatile and lipophilic components, they are susceptible to light, heat and air, and thus to conversion and degradation [Yuan et al., 2019]. Beyond that, their poor stabilities also lead to difficult storage and transportation.

Consequently, stability enhancement methods of LEO are essential to expand the applications. Microencapsulation

\footnotetext{
* Corresponding Author e-mail: tanjin@tjcu.edu.cn (J. Tan)
}

technologies for essential oil have raised concern in biology, medicine and food researches in the last few years. As common wall materials for microencapsulation, cyclodextrins (CDs) are a class of cyclic oligosaccharides normally produced from starch under the effect of the enzyme catalytic reaction [Thombre et al., 2013]. CDs are characterized by their amphiphilic structure with hydrophobic inner cavity and hydrophilic outer wall, which could embed guest molecules to form relatively stable complexes [Tian et al., 2020]. They are mainly composed of 6,7 or 8 glucose units, known as $\alpha-, \beta$ and $\gamma$-CD, respectively [Thombre et al., 2013]. Among them, $\beta-\mathrm{CD}$ is one of the most important members and is derived from $7 \mathrm{D}(+)$-glucose units linked by $\alpha$-1,4-glycosidic bonds [Thombre et al., 2013]. Comparing with other CDs, $\beta$-CD is the most frequently used CD due to the lowest price and relatively appropriate size cavity. The interest in $\beta$-CD regarding its food-related applications has been increasing since it was approved for food uses by FDA [Partanen et al., 2002]. With cavity, $\beta$-CD could act as a host and include some molecules as guests to form inclusion complexes by van der Waals and hydrophobic interaction forces, or hydrogen bonds [Deng et al., 2018]. However, the applications of $\beta$-CD are limited by its relatively low binding capacity and solubility. Therefore, the metal-organic frameworks (MOFs) with the utilization of the special structure of CDs were developed to solve the above problems. CD-MOFs are network-structure and crystalline porous materials derived from CDs and metal ions or clusters for biomedical applications [Li et al., 2017; Smaldone et al., 2010]. They have high porosity, large surface areas, and ver- 
satility in terms of composition and functionalities [Li \& Huo, 2015]. Particularly, K- $\beta$ CD-MOFs could be synthesized from $\beta-\mathrm{CD}$ and $\mathrm{K}$ ions employing a vapor diffusion method [Smaldone et al., 2010]. The K- $\beta \mathrm{CD}-\mathrm{MOF}$ have good cutting structure, high drug loading capacity and strong inclusion ability, in addition, they are environment-friendly, biocompatible and without side-effects on the human body [Abuçafy et al., 2018; Liu et al., 2017]. Kumar et al. [2020] reviewed that MOFs could be widely applied to various areas including catalysis, energy storage, solar cells, air and water purification, gas storage, bioimaging, drug delivery, waste remediation and sensors. So far, MOFs are rarely applied in food, however, K- $\beta C D-M O F s$ are recognized due to their non-toxicity and unique "food-grade synthesis" based on natural components [Kumar et al., 2020]. Therefore, the potential of K- $\beta \mathrm{CD}-\mathrm{MOF}$ as microcapsule wall materials is huge and the application prospects are also broad, especially possible in food.

To our best knowledge, limited researches were done on the essential oil stability improvement using CDs or MOFs related materials. For example, Yuan et al. [2019] reported LEO encapsulated in hydroxypropyl- $\beta$-cyclodextrin (HPCD) and Wu et al. [2019] investigated zinc metal-organic framework ( $\mathrm{Zn} @ \mathrm{MOF})$ as a carrier for thymol. There is no research hitherto on the stability improvement of LEO by microencapsulation by K- $\beta C D-M O F s$. Furthermore, whether the microencapsulation by K- $\beta C D-M O F s$ affects the antioxidant activities of LEO is also important for further applications of the oil. Therefore, LEO was microencapsulated by $\mathrm{K}-\beta \mathrm{CD}-\mathrm{MOF}$ to improve the stability and thereby expand the applications. The thermal $/ \mathrm{pH}$ stabilities and intracellular antioxidant activities were also determined and compared, and the inclusion compound was further identified by Fourier transform infrared spectroscopy (FTIR) and scanning electron microscopy (SEM).

\section{MATERIALS AND METHODS}

\section{Apparatus}

A blade homogenizer A10 (IKA, Staufen, Germany) was used to ground the plants. An ultrasonic-microwave assisted extraction (UMAE) apparatus CW-2000 (Xintuo, Shanghai, China) was used for the extraction of lavender essential oil. The absorbances for the inclusion rate and stability measurement were determined by an ultraviolet and visible spectrophotometer Lambda25 (PerkinElmer, Waltham, MA, USA). Cell proliferation was measured using a SpectraMax M5 96-well plate reader (Molecular Devices, Sunnyvale, CA, USA). A Fourier transform infrared spectroscope IRAffinity-1 (Shimadzu, Tokyo, Japan) and a scanning electron microscope JSM-IT300 (JEOL, Tokyo, Japan) were used to characterize the essential oil included in the molecular microcapsules. Morphological characteristics of $\beta-\mathrm{CD}$ and $\mathrm{K}-\beta \mathrm{CD}-\mathrm{MOFs}$ were observed and photographed by an optical microscope (Smart, Chongqing, China).

\section{Chemicals}

$\beta-\mathrm{CD}$ and dimethylsulfoxide (DMSO) were purchased from Tianjin Chemical Factory (Tianjin, China). HeLa cells were purchased from the Institute of Biochemistry and Cell
Biology (Shanghai, China). The fetal bovine serum (FBS) and Dulbecco's modified eagle's medium (DMEM) were obtained from Gibco Co. (Carlsbad, CA, USA). Double-antibody (penicillin-streptomycin) was purchased from HyClone Co. (South Logan, UT, USA). Methyl thiazolyl tetrazolium (MTT) was purchased from Solarbio Biotechnology Co. (Beijing, China). 2',7'-Dichlorofluorescein diacetate (DCFH-DA) assay kit was purchased from Beyotime Institute of Biotechnology (Shanghai, China). Distilled water was used throughout the experiment. $\mathrm{KBr}$ was of spectral purity and was purchased from Tianjin Chemical Factory (Tianjin, China). Other chemicals or reagents were all of analytical grade.

\section{Plant materials and essential oil extraction}

The lavender (Lavandula angustifolia) aerial parts were purchased from Xinjiang province, China. The plants were ground, sieved to 40 mesh, and stored in cool and dry place. LEO was then extracted by ultrasonic-microwave assisted extraction (UMAE) following our previous work [Wang et al., 2018] with modifications. The extraction temperature, microwave power, ultrasonic power, extraction time and the ratio of plant material to liquid were $100^{\circ} \mathrm{C}, 600 \mathrm{~W}, 50 \mathrm{~W}, 7 \mathrm{~min}$ and 1:10 $(\mathrm{g} / \mathrm{mL})$, respectively. The mean values of the LEO yields were $3.27 \%$ based on dry weights.

\section{Synthesis of K- $\beta C D$-MOFs}

The high purity $\beta$-CD crystals were obtained by the following steps. First, $\beta$-CD was dissolved in distilled water heated to $85^{\circ} \mathrm{C}$ to form a saturated solution, cooled down, and then the crystals were collected by filtration. The above operation was repeated three times and the crystals were combined and oven-dried at $100^{\circ} \mathrm{C}$.

$\mathrm{K}-\beta \mathrm{CD}-\mathrm{MOF}$ were synthesized based on the above purified $\beta$-CD crystals according to the methanol vapor diffusion method with some modifications [Smaldone et al., 2010]. Briefly, $1.1349 \mathrm{~g}$ of purified $\beta-\mathrm{CD}$ were dissolved with $0.4488 \mathrm{~g}$ of potassium hydroxide $(\mathrm{KOH})$ in distilled water. This solution was transferred into a beaker after filtration and then sealed in a tank with $100 \mathrm{~mL}$ of methanol for one week. This operation aimed to allow the vapor of methanol diffuse into the solution and form K- $\beta C D$-MOFs. The formed $\mathrm{K}-\beta \mathrm{CD}-\mathrm{MOFs}$ are relatively rectangular, colorless and transparent crystals. The K- $\beta C D-M O F s$ crystals were then washed twice with $30 \mathrm{~mL}$ of methanol. K- $\beta C D$-MOFs and $\beta$-CD were observed under an optical microscope for their basic morphological characteristics.

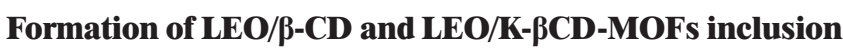 complexes}

The lavender essential oil (LEO) as a core was microencapsulated by K- $\beta C D-M O F s$ as wall materials to form the inclusion complexes by different mass core/wall ratios (1:3, 1:5, 1:8, 1:10 and 1:12) following Michida et al. [2015] with modification. Briefly, $1 \mathrm{mg} / \mathrm{mL}$ of the LEO solution was prepared by dissolving the oil in $45 \%$ ethanol, while K- $\beta C D-$ -MOFs were dissolved in isovolumetric distilled water. The oil solution was then added and dispersed into the $\beta$-CD-MOFs solution dropwise with stirring at $48^{\circ} \mathrm{C}$ to ensure thorough mixing and optimum inclusion. The mixture was cooled down 
and freeze-dried to obtain the white powdered inclusion complex product. The inclusion rate was calculated as follows:

Inclusion rate $(\%)=\left(1-\mathrm{As}_{\mathrm{LEO}} / \mathrm{At}_{\mathrm{LEO}}\right) \times 100 \%$

where: As ${ }_{\text {LEO }}$ and At ${ }_{\text {LEO }}$ were the amount of LEO on the surface of inclusion complex and the total amount of LEO in the inclusion complex, respectively. The former was calculated by the following steps: $0.05 \mathrm{~g}$ of $\mathrm{LEO} / \mathrm{K}-\beta \mathrm{CD}-\mathrm{MOF}$ powder with each mass core/wall ratio was transferred into a $100 \mathrm{~mL}$ volumetric flask, and anhydrous ether was added, then the sample was shaken and made up to the volume. After sufficient mixing, the surface of the complex powder was thoroughly washed. After filtration, the absorbance of the supernatant was measured at $233 \mathrm{~nm}$, which is the maximum absorption wavelength of LEO. $\mathrm{At}_{\mathrm{LEO}}$ was determined as follows: $0.05 \mathrm{~g}$ of LEO/K- $\beta \mathrm{CD}-\mathrm{MOF}$ powder with each mass core/wall ratio was ultrasonically $(60 \mathrm{~W})$ dissolved by $100 \mathrm{~mL}$ of $45 \%$ ethanol for $30 \mathrm{~min}$. After thorough dissolution and filtration, the absorbance of the supernatant was also measured at $233 \mathrm{~nm}$. Both the amounts of the surface and total LEO were calculated using a standard curve of linalool, which is the main component of LEO [Dong et al., 2020]. The inclusion rate was also optimized by comparison among different mass core/wall ratios. The LEO/ $\beta$-CD inclusion complex was also produced according to the previous steps with the core/wall ratio of 1:10, which was the optimum ratio for the $\mathrm{LEO} / \mathrm{K}-\beta \mathrm{CD}-\mathrm{MOFs}$ production.

\section{Properties of LEO, LEO/ $\beta$-CD and LEO/K- $\beta$ CD-MOFs}

\section{Thermal stability and $p H$ stability measurements}

The LEO, LEO/ $\beta-C D$ and LEO/K- $\beta C D-M O F s$ solutions were prepared by dissolving them in $45 \%$ ethanol. Their concentration was $0.1 \mathrm{mg} / \mathrm{mL}$ (LEO equivalence). The actual concentrations of the latter two complexes were ten-fold of LEO, as the mass optimum core/wall ratio was 1:10. The three solutions were stored in an oven at $90^{\circ} \mathrm{C}$ in dark for 10 days. The absorbances of the above solutions were measured at $233 \mathrm{~nm}$ every $24 \mathrm{~h}$ to study the change of LEO amounts. The preservation rates of $\mathrm{LEO}, \mathrm{LEO} / \beta-\mathrm{CD}$ and $\mathrm{LEO} / \mathrm{K}-\beta \mathrm{CD}$ -MOFs to the original LEO amounts were calculated using the following equation:

Preservation rate $(\%)=\mathrm{A}_{\text {thermal }} / \mathrm{A}_{\mathrm{c}} \times 100 \%$

where: $A_{\text {thermal }}$ was the absorbance of LEO after heating, while $A_{c}$ was the absorbance of LEO control sample without temperature treatment.

The $\mathrm{pH}$ values of $\mathrm{LEO}, \mathrm{LEO} / \beta-\mathrm{CD}$ and $\mathrm{LEO} / \mathrm{K}-\beta \mathrm{CD}$ -MOFs solutions were adjusted by phosphate buffer to 3 , 7 and 10, respectively. The three solutions were prepared as mentioned above. The adjusted solutions were stored in the dark at $25^{\circ} \mathrm{C}$ for 10 days. The absorbances of the solutions were measured at $233 \mathrm{~nm}$ every $24 \mathrm{~h}$ to study the change of LEO amounts. The preservation rates of LEO, LEO/ $\beta-C D$ and $\mathrm{LEO} / \mathrm{K}-\beta \mathrm{CD}-\mathrm{MOF}$ to the original LEO amounts were calculated similarly to the above equation mentioned in the thermal stability measurement.

\section{Intracellular antioxidant activity}

No mycoplasma contaminations of HeLa cells were guaranteed by using Young et al.'s [2010] mycoplasma testing method. The cell viability and intracellular antioxidant activity were measured according to the previous method described in our earlier works [Wang et al., 2019; Yang et al., 2013] with some modifications. HeLa cells were transferred into a 96-well plate at a density of $1 \times 10^{5}$ per well in $100 \mu \mathrm{L}$ of growth medium. The growth medium was pre-prepared by mixing $45 \mathrm{~mL}$ of DMEM, $5 \mathrm{~mL}$ of FBS and $500 \mu \mathrm{L}$ of double-antibody. Cells were incubated with $5 \% \mathrm{CO}_{2}$ for $24 \mathrm{~h}$ at $37^{\circ} \mathrm{C}$. After removal of the medium, the cells were washed by a phosphate buffer solution (PBS) $(\mathrm{pH}=7.4)$, and then treated with $100 \mu \mathrm{L}$ of different concentrations $(0.001-2 \mu \mathrm{L} / \mathrm{mL}$, LEO equivalence) of LEO or included LEO (LEO/ $\beta-\mathrm{CD}$ and LEO/K- $\beta C D$-MOFs) for another $24 \mathrm{~h}$. For operation convenience in the cell experiments, the essential oil samples were measured in volume concentration i.e., " $\mu \mathrm{L} / \mathrm{mL}$ ". The mass of LEO can be calculated by its volume multiplied by its density $(0.85 \mathrm{~g} / \mathrm{mL})$. The actual concentrations of $\mathrm{LEO} / \beta-\mathrm{CD}$ and $\mathrm{LEO} / \mathrm{K}-\beta \mathrm{CD}-\mathrm{MOF}$ in all experiments were ten-fold of LEO, as the mass optimum core/wall ratio was 1:10. However, to enable further comparisons, the concentrations of these three were all expressed in " $\mu \mathrm{L} / \mathrm{mL}$, LEO equivalence". Different concentrations of the LEO were dissolved in different concentrations of DMSO, i.e., $0.001,0.01$ and $0.1 \mu \mathrm{L} / \mathrm{mL}$ in $0 \%$ DMSO, $0.2 \mu \mathrm{L} / \mathrm{mL}$ in $2 \%$ DMSO, $0.4 \mu \mathrm{L} / \mathrm{mL}$ in $4 \% \mathrm{DMSO}, 0.5 \mu \mathrm{L} / \mathrm{mL}$ in $5 \%$ DMSO, $1 \mu \mathrm{L} / \mathrm{mL}$ in $10 \%$ DMSO, $2 \mu \mathrm{L} / \mathrm{mL}$ in $20 \%$ DMSO, respectively. For LEO/ $/ \beta-\mathrm{CD}, 0.001-1 \mu \mathrm{L} / \mathrm{mL}$ were dissolved in $0 \% \mathrm{DMSO}$, and $2 \mu \mathrm{L} / \mathrm{mL}$ was dissolved in $2 \%$ DMSO. LEO/K- $\beta$ CD-MOFs were directly dissolved in the medium. Therefore, the corresponding concentrations of DMSO were used as solvent controls for the cell viability and intracellular antioxidant activity experiments. The control was added with the growth medium instead of the samples. After PBS washing again, $5 \mathrm{mg} / \mathrm{mL}$ of MTT was added for another 4-h incubation. Subsequently, $150 \mu \mathrm{L}$ of DMSO was added to dissolve the crystals, and the absorbance was then measured at $570 \mathrm{~nm}$.

In the intracellular antioxidant activity experiment, HeLa cells were transferred and incubated according to the same procedures in cell viability assay. An aliquot of $100 \mu \mathrm{L}$ of $20 \mu \mathrm{M}$ DCFH-DA was mixed with $100 \mu \mathrm{L}$ of $0.1 \mu \mathrm{L} / \mathrm{mL}$ of the LEO or included LEO (LEO/ $\beta-\mathrm{CD}$ and $\mathrm{LEO} / \mathrm{K}-\beta \mathrm{CD}$ -MOFs) solution for $1 \mathrm{~h}$. After the wells were washed by PBS ( $\mathrm{pH}=7.4), 100 \mu \mathrm{L}$ of $200 \mu \mathrm{M} \mathrm{H}_{2} \mathrm{O}_{2}$ was added into each well. The fluorescence intensities were measured every $5 \mathrm{~min}$ during the 1-h incubation time, and the integral area of the relative fluorescence intensity was calculated and marked as $\int$ SA. The excitation and emission wavelengths were 525 and $488 \mathrm{~nm}$, respectively. When the growth medium was added instead of the samples, the integral area of the relative fluorescence intensity was $\int \mathrm{CA}$. The blank was prepared without both the samples and $\mathrm{H}_{2} \mathrm{O}_{2}$ solution. The intracellular antioxidant activity (CAA) was calculated according to the following equation:

$\mathrm{CAA}(\%)=100-\left(\int \mathrm{SA} / \int \mathrm{CA}\right) \times 100$ 

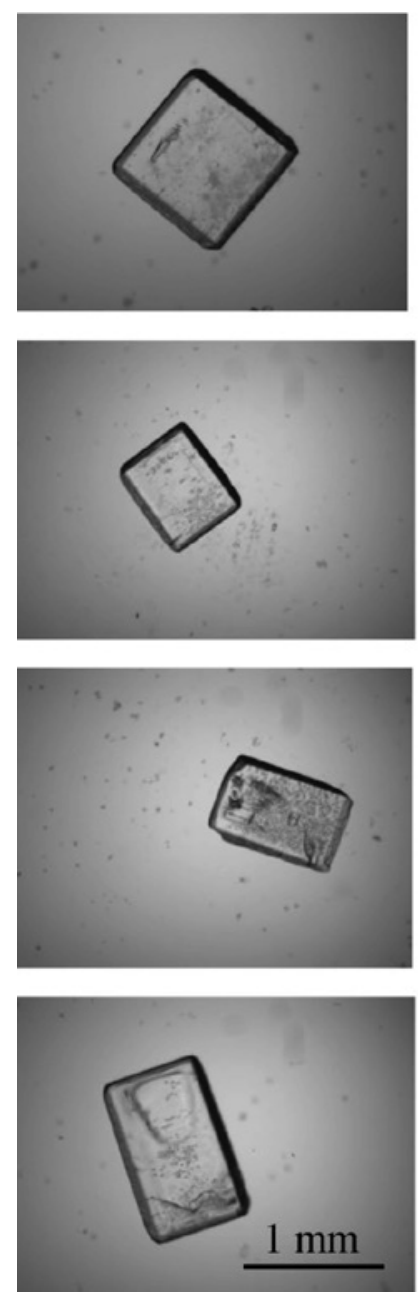

$\beta-C D$
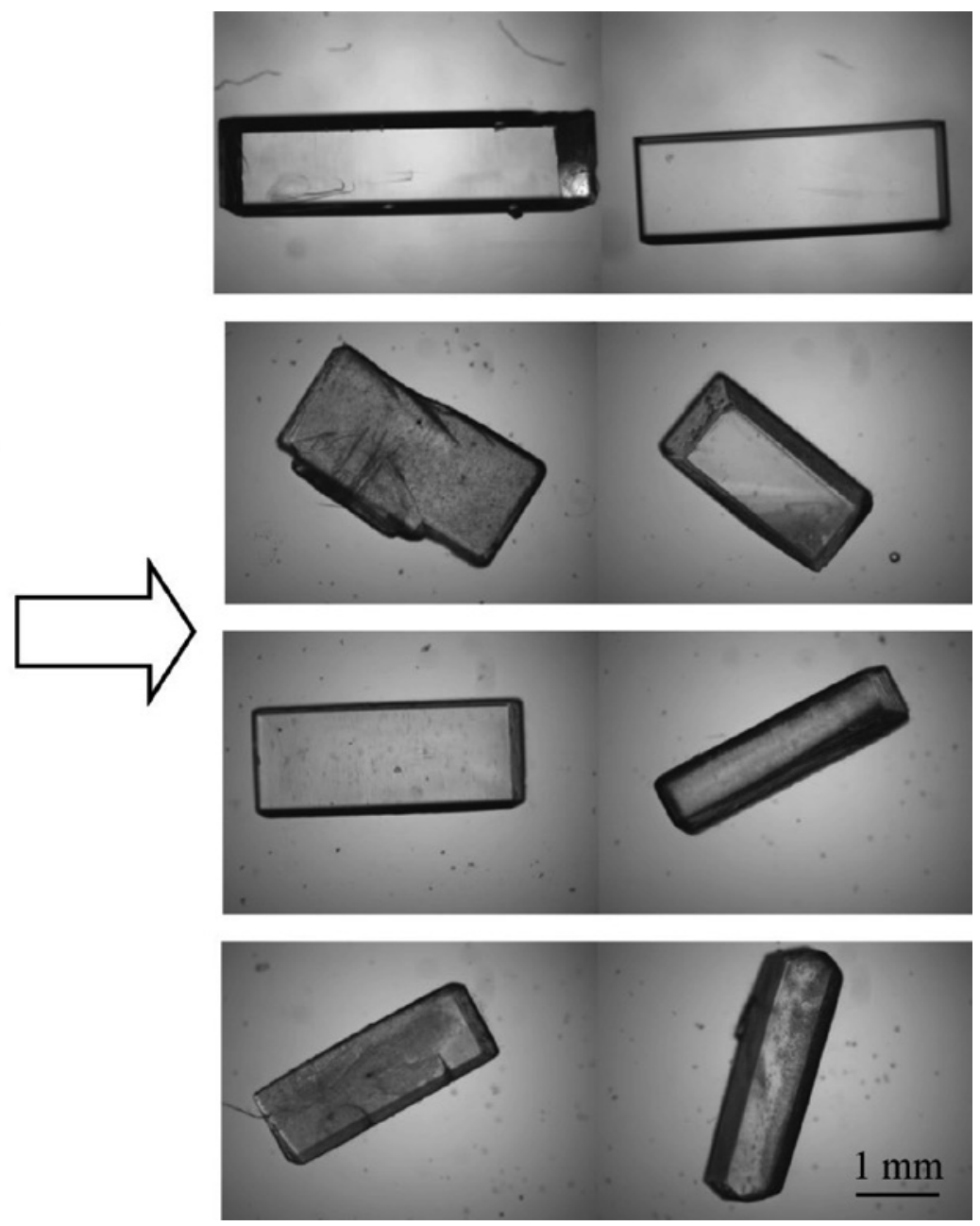

K-BCD-MOFs

FIGURE 1. Optical microscope pictures of purified $\beta$-CD and metal-organic frameworks based on $\beta$-cyclodextrin and potassium cation (K- $\beta C D-M O F s$, magnification is 40 times).

\section{Fourier transform infrared spectroscopy (FTIR)}

The LEO, LEO/ $\beta-C D$ and LEO/K- $\beta$ CD-MOFs inclusion, as well as the physical mixture of LEO and K- $\beta C D$ -MOFs were analyzed by FTIR, which was conducted by $\mathrm{KBr}$ direct compression method, i.e., $1 \mathrm{mg}$ of the sample was ground together with $\mathrm{KBr}$ (about $100 \mathrm{mg}$ ) into a fine powder, and compressed into the holder using a compression gauge. The liquid LEO was given a drop on the surface of $\mathrm{KBr}$. The inclusion complexes were cleaned with petroleum ether 3 times to ensure no presence of LEO on the surface. The spectra were scanned within the wavelength 4,000 to $450 \mathrm{~cm}^{-1}$. The number of scans and spectral resolution were 5 scans and $4 \mathrm{~cm}^{-1}$, respectively.

\section{Scanning electron microscope (SEM)}

Besides the microscope observations, the morphological characterization of K- $\beta C D-M O F s$ and $\mathrm{LEO} / \mathrm{K}-\beta \mathrm{CD}-\mathrm{MOFs}$ was further carried out by SEM analysis. Material particles were fixed on the silicon wafer and sprayed with a $100 \mathrm{~nm}$-thick gold. The microstructures of the samples, such as the shapes and surface characteristics, were then observed and photographed using the SEM.

\section{Statistical analyses}

The inclusion rates of LEO to $\beta-\mathrm{CD}$ or K- $\beta \mathrm{CD}$-MOFs in the inclusion complexes were compared among the different mass core/wall ratios by one-way ANOVA, followed by a post-hoc multiple comparison (Tukey's Test). One-way ANOVA was also performed to compare the differences among LEO, $\mathrm{LEO} / \beta-\mathrm{CD}$ and $\mathrm{LEO} / \mathrm{K}-\beta \mathrm{CD}-\mathrm{MOF}$ at the same concentration (concentrations of the two including LEO were expressed as LEO equivalence) in thermal and $\mathrm{pH}$ stabilities, cell viabilities, as well as CAA. All statistical analyses were performed using the Statistical Package for Social Science (SPSS) version 16.0. Three replicates with mean values and standard deviations were carried out for all statistical analyses.

\section{RESULTS AND DISCUSSION}

\section{Formation of K-BCD-MOFs}

The K- $\beta C D-M O F s$ were produced from the purified $\beta$-CD by the methanol diffusion method. The morphology features of their crystal structures were compared using an optical microscope $(\times 40)$ and shown in Figure 1. They were both relatively regular and transparent with a neat appear- 
ance. The $\beta$-CD showed shorter rectangular shape, while the $\mathrm{K}-\beta \mathrm{CD}-\mathrm{MOF}$ were larger and longer.

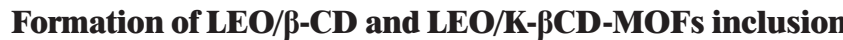 complexes}

Based on the formation of the wall material K- $\beta C D$ -MOFs, LEO was microencapsulated as the core to produce inclusion complexes in different mass core/wall ratios. The inclusion rates of LEO/K- $\beta \mathrm{CD}-\mathrm{MOF}$ were shown in Figure 2. The inclusion rate increased significantly with the increase of the ratio, i.e., with the increasing mass of wall material (K- $\beta C D-M O F s)$, the inclusion rate of LEO to the wall significantly increased. The inclusion rate reached up to $93.45 \%$ with the core/wall ratio of 1:10, while no significant changes were observed for the rate of $95.67 \%$ with ratio of $1: 12$. Therefore, to save the resource and energy, the mass core/wall ratio of $1: 10$ was used for the future formation of $\mathrm{LEO} / \mathrm{K}-\beta \mathrm{CD}-\mathrm{MOF}$ complexes. In addition, the inclusion rates of LEO to K- $\beta C D$ -MOFs and $\beta-C D$ were also compared with the ratio of 1:10. The latter was only $78.42 \%$, which was significantly lower than the rate of $\mathrm{LEO} / \mathrm{K}-\beta \mathrm{CD}-\mathrm{MOF}$ with the same ratio.

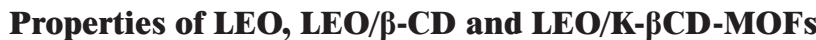

\section{Thermal stability}

The changes of LEO, LEO/ $\beta-\mathrm{CD}$ and $\mathrm{LEO} / \mathrm{K}-\beta \mathrm{CD}$ -MOFs inclusion complexes under heat treatment at $90^{\circ} \mathrm{C}$ were studied during 10-day period with 1-day interval. After 24-h heat treatment, the preservation rate of LEO decreased to $53.27 \%$, while the rate of $\mathrm{LEO}$ in the $\mathrm{LEO} / \mathrm{K}-\beta \mathrm{CD}-\mathrm{MOF}$ complex still remained at $90.13 \%$ (Figure $3 \mathrm{~A}$ ). As the heating time went on, the preservation rate of LEO and its inclusion complexes kept a gradually decreasing trend, with LEO's rate

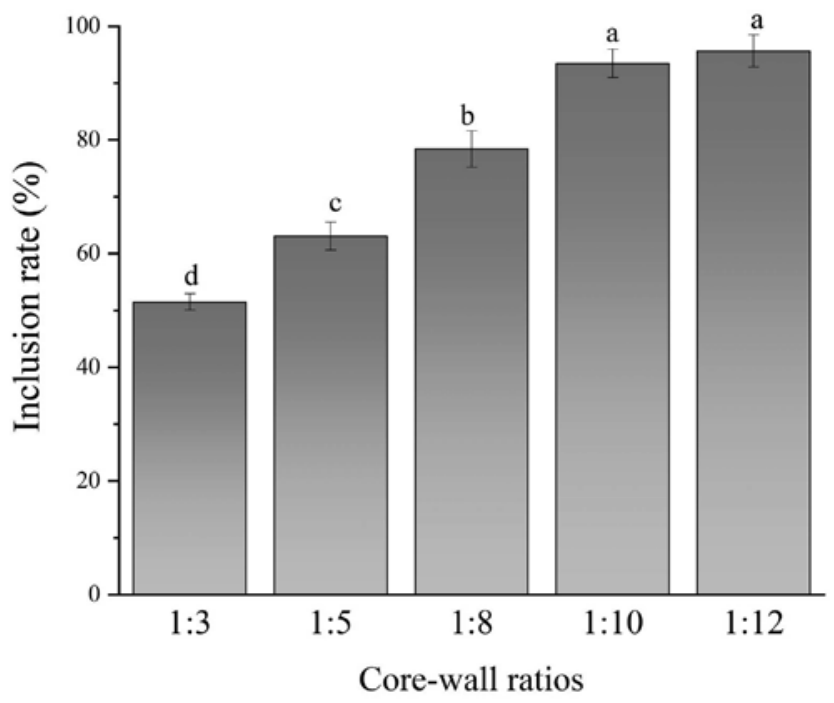

FIGURE 2. The inclusion rate of lavender essential oil (LEO) to metal-organic frameworks based on $\beta$-cyclodextrin and potassium cation (K- $\beta$ CD-MOFs) under different core/wall ratios.

Bars with different lower-case letters show significant differences of inclusion rate among different core/wall ratios at $\mathrm{p} \leq 0.05$ according to one-way ANOVA test. Data are reported as the mean $\pm \mathrm{SD}$ of three replicates.

decreasing more rapidly and significantly than those of the complexes (Figure $3 \mathrm{~A}$ ). After 10 days, the preservation rate of $\mathrm{LEO} / \mathrm{K}-\beta \mathrm{CD}-\mathrm{MOFs}$ and $\mathrm{LEO} / \beta-\mathrm{CD}$ remained at 66.88 and $31.50 \%$, respectively, while the rate of LEO was only $18.00 \%$ in the same environment (Figure 3A). The thermal stability of LEO could be significantly improved by embedding with $\beta-\mathrm{CD}$ and $\mathrm{K}-\beta \mathrm{CD}-\mathrm{MOF}$, especially the latter. These phenomena suggested that K- $\beta \mathrm{CD}-\mathrm{MOF}$ could provide better pro-
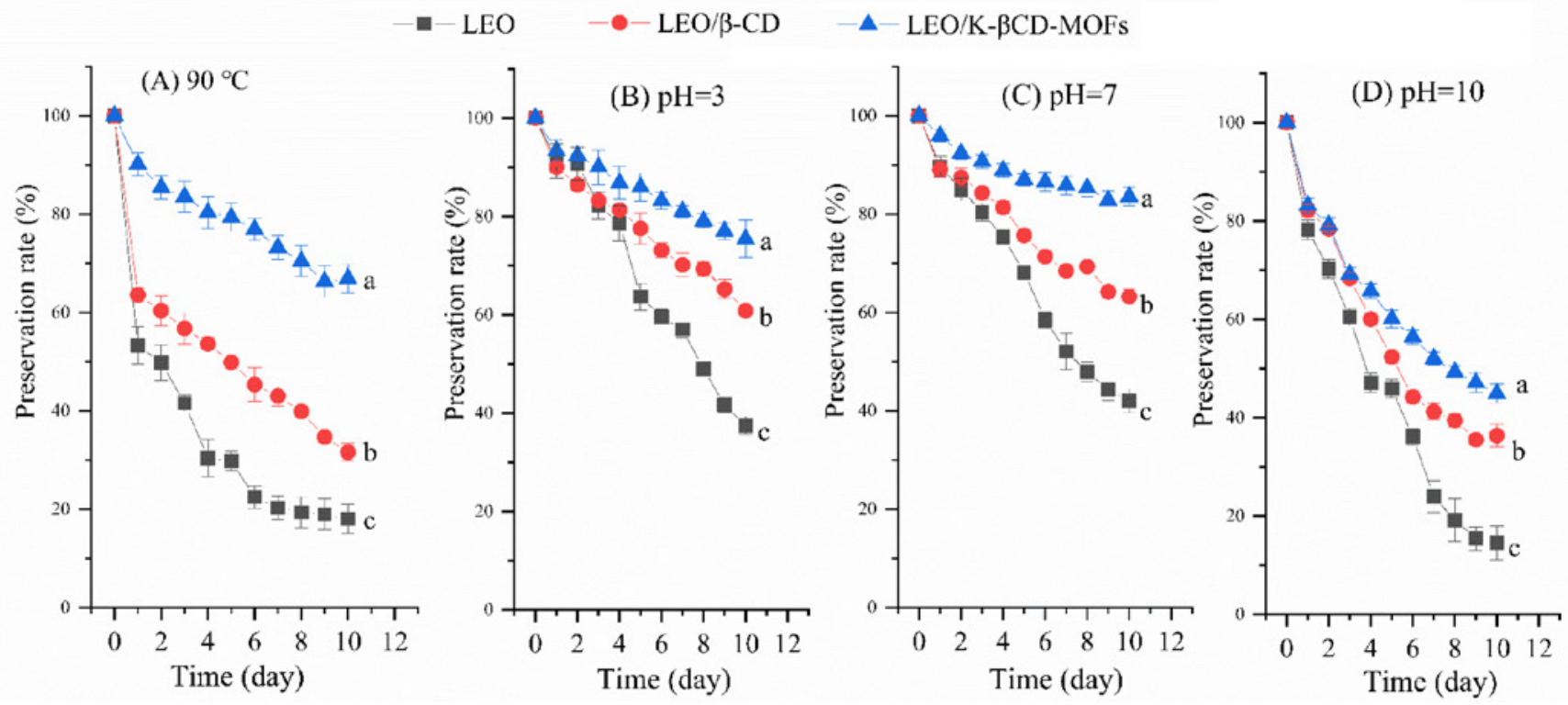

FIGURE 3. Thermal- (A) and pH-stabilities (B, C and D) of lavender essential oil (LEO), LEO/ $\beta$-cyclodextrins (LEO/ $\beta$-CD) and LEO/metal-organic frameworks based on $\beta$-cyclodextrin and potassium cation (LEO/K- $\beta \mathrm{CD}-\mathrm{MOFs}$ ) inclusion complexes.

The LEO/ $\beta$-CD and LEO/K- $\beta C D-M O F s$ inclusion complexes with core/wall ratio of 1:10 were used. Lines with different lower-case letters show significant differences of preservation rate at day 10 among LEO, LEO/ $\beta-C D$ and $L E O / K-\beta C D-M O F s$ under the same conditions at $p \leq 0.05$ according to one-way ANOVA test. Data are reported as the mean \pm SD of three replicates. 
tection for LEO than $\beta$-CD against evaporation/degradation after LEOs were embedded. This could be explained by the improved thermal stability of both LEO and $\beta$-CD rendered by K- $\beta C D-M O F s$. Han et al. [2018] reported that the structures of $\mathrm{CDs}$ were modified, and the CD-MOFs were more thermally stable in an aqueous medium or in the physiological environment, as well as showed preferable solubility in water. Lv et al. [2017] reported that sucralose degraded very fast at $90^{\circ} \mathrm{C}$ for only one hour with about $14 \%$ left, while the stability of sucralose was dramatically enhanced by CD-MOFs, with only $13.7 \%$ decomposition under the same heat environment within $24 \mathrm{~h}$. Furthermore, for future and better applications of LEO, the thermal stabilities of the inclusion complexes under many other thermal conditions and different working temperature (e.g., 50, 75, 100 and $121^{\circ} \mathrm{C}$ ) should be studied.

\section{pH stability}

The results of the influence of different $\mathrm{pH}$ values (3, 7 and 10) on the stabilities of LEO, LEO/ $\beta$-CD and LEO/ $\beta$-CD-MOFs were obtained during 10-day period, and the variation trends of the preservation rate were shown in Figure 3B, C, D. Under acidic and neutral conditions, the stabilities of LEO and its inclusion complexes were better than under alkali condition, and the acid resistance of LEO/ $\beta-\mathrm{CD}$ and $\mathrm{LEO} / \beta-\mathrm{CD}-\mathrm{MOFs}$ was much stronger than that of LEO itself (Figure. 3B, C). In strong alkali environment, the stabilities of LEO and LEO inclusion complexes decreased sharply. However, the stabilities of these complexes were still stronger than that of non-included LEO (Figure 3D). Therefore, in general, $\mathrm{LEO} / \beta-\mathrm{CD}$ and $\mathrm{LEO} / \beta-\mathrm{CD}-\mathrm{MOF}$ exhibited better acid-alkali resistance stabilities than the original oil, with better applicability under neutral and acidic conditions. This result can be attributed to the fact that the essential oils are always stable in weak acidic to neutral environment and are often applied in acidic conditions [Bensouda et al., 2019; Wang et al., 2009].

\section{Intracellular antioxidant activities}

Reduction reaction of MTT occurs with the presence of succinodehydrogenase in living cells, and MTT changes from yellow tetrazolium salt to purple formazan. Therefore, the absorbance at the maximum absorption wavelength of $570 \mathrm{~nm}$ of the purple product could indirectly reflect the amount of the living cells [Adach et al., 2016]. The effects of the different concentrations of LEO, LEO/ $\beta$-CD and LEO/K- $\beta$ CD-MOFs on the cell viabilities of HeLa cells were analyzed (Figure 4). Within the concentration range from 0.001 to $0.2 \mu \mathrm{L} / \mathrm{mL}$, no significant difference was found among LEO, LEO/ $\beta$-CD and LEO/K- $\beta$ CD-MOFs. Both LEO and its inclusion complexes did not pose negative effects on the HeLa cell viabilities with concentrations lower than $0.2 \mu \mathrm{L} / \mathrm{mL}$. However, the HeLa cell viabilities decreased with the concentration higher than $0.4 \mu \mathrm{L} / \mathrm{mL}$. The inhibitory effects on cell viabilities of $\mathrm{LEO} / \mathrm{K}-\beta \mathrm{CD}-\mathrm{MOFs}$ were significantly higher than those of LEO at concentration $0.4,0.5$ and $1 \mu \mathrm{L} / \mathrm{mL}$, and also significantly higher than $\mathrm{LEO} / \beta-\mathrm{CD}$ at $0.5 \mu \mathrm{L} / \mathrm{mL}$. All the samples showed similar inhibitions on HeLa cells with the highest concentration at $2 \mu \mathrm{L} / \mathrm{mL}$. The growth and viabilities of HeLa cells were inhibited, indicating the lavender essential oil could play an anticancer role with the concentrations reaching up to $0.4 \mu \mathrm{L} / \mathrm{mL}$. Previous studies showed potential anticancer and antiproliferative activities of LEO by the induction of apoptosis and necrosis of cancer cells [Gezici, 2018]. LEO also exhibited on antitumor effects on the human prostate cancer, and its antitumor effect was associated with cell proliferation inhibition and apoptosis induction in xenograft tumors [Zhao et al., 2017]. Besides, the components of LEO also showed anticancer and antitumor effects. For example, one constituent of lavender oil - perillyl alcohol - has recently been identified as a potential anticancer agent, which may be useful in both treatment and prevention [Liston et al., 2003; Samaila et al., 2004]. Linalool and linalyl acetate also showed strong inhibitory effects on human prostate cancer PC-3 and DU145 cells [Zhao et al., 2017]. Usta et al. [2009] reported that linalool could decrease the viability of HepG20 to 50\% and $0 \%$ by concentrations of $4 \mu \mathrm{M}$ and $2 \mu \mathrm{M}$, respectively. Differences in the inhibitory activity of LEO and its microcapsules were in the order $\mathrm{LEO} / \beta-\mathrm{CD}-\mathrm{MOFs}>\mathrm{LEO} / \beta-\mathrm{CD}$ $>$ LEO, and could be easily ascribed to the higher solubility of $\beta$-CD-MOFs than $\beta$-CD [Han et al., 2018], as well as the higher solubility of the complexes than LEO itself. All these related to the potential applications of LEO as potential anticancer/antitumor agents deserve further researches. Besides the anticancer role of LEO in killing HeLa cells, in the present study we focused on whether the intracellular antioxidant activities of LEO could be improved by microencapsulation by K- $\beta C D$-MOFs.

Although the chemical methods used to evaluate antioxidant activities in vitro are easy, convenient and inexpensive, they could reflect neither the antioxidant activities of the anti-

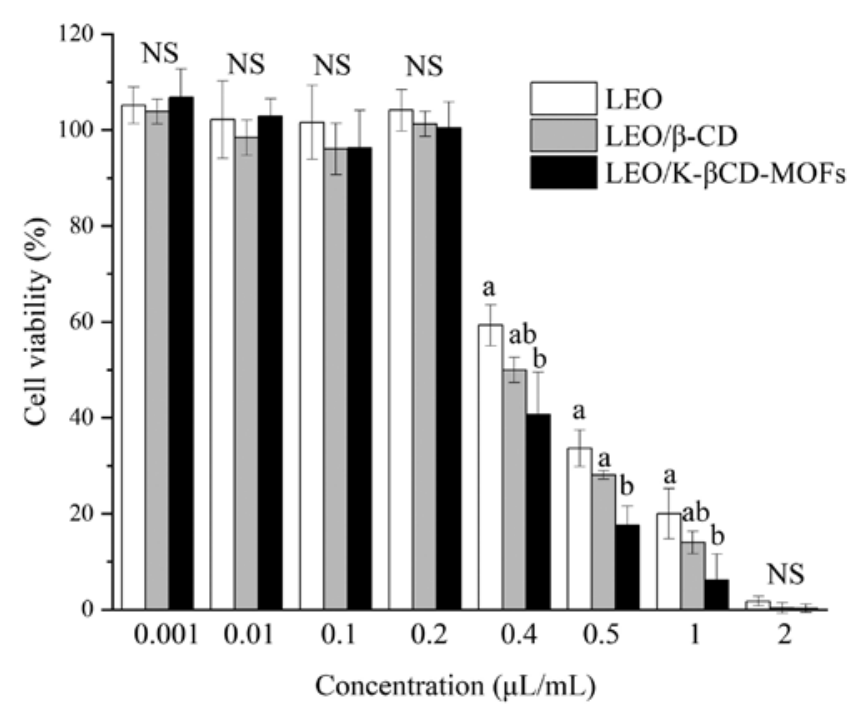

FIGURE 4. Effects of lavender essential oil (LEO), LEO/ $\beta$-cyclodextrins (LEO/ $\beta$-CD) and $\mathrm{LEO} /$ metal-organic frameworks based on $\beta$-cyclodextrin and potassium cation (LEO/K- $\beta \mathrm{CD}-\mathrm{MOFs}$ ) inclusion complexes on cell viability in HeLa cells.

The LEO/ $\beta-\mathrm{CD}$ and LEO/K- $\beta \mathrm{CD}-\mathrm{MOFs}$ inclusion complexes with core/ wall ratio of 1:10 were used. Bars with different lower-case letters show significant differences among the effects of LEO, LEO/ $\beta-C D$ and LEO/ $\mathrm{K}-\beta \mathrm{CD}-\mathrm{MOF}$ on cell viability at $\mathrm{p} \leq 0.05$ according to one-way ANOVA test. NS: Not significant difference. Data are reported as the mean \pm SD of three replicates. 

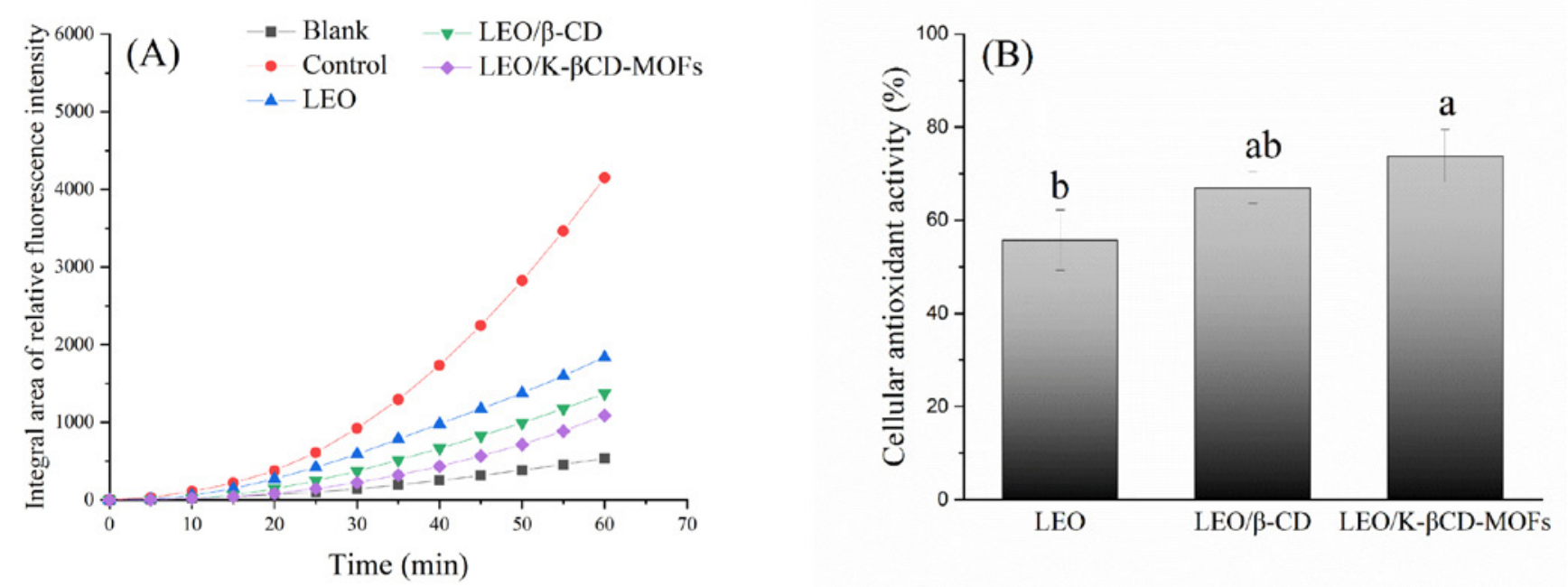

FIGURE 5. The integral areas of relative fluorescence intensity (A) and the intracellular antioxidant activity (CAA) of lavender essential oil (LEO), $\mathrm{LEO} / \beta$-cyclodextrins (LEO/ $\beta$-CD) and $\mathrm{LEO} /$ metal-organic frameworks based on $\beta$-cyclodextrin and potassium cation (LEO/K- $\beta \mathrm{CD}-\mathrm{MOFs}$ ) $\mathrm{B}$ ) in HeLa cells.

The LEO/ $\beta$-CD and LEO/K- $\beta C D$-MOFs inclusion complexes with core/wall ratio of 1:10 were used. Bars with lower-case letters show significant differences among LEO, LEO/ $\beta-\mathrm{CD}$ and LEO/K- $\beta \mathrm{CD}-\mathrm{MOF}$ at $\mathrm{p} \leq 0.05$ according to one-way ANOVA. Data are reported as the mean $\pm \mathrm{SD}$ of three replicates.

oxidants in vivo nor the real physiological environment of the human body. On the other hand, animal models or even human experiments are relatively expensive and time-consuming. Cell model could predict the antioxidant capacities of the antioxidants in the human body more accurately than chemical methods. Therefore, the cell model method is a good choice to simulate the internal physiological environment of the human body, study the intracellular antioxidant activities, and provide an economical and rapid method for better antioxidant research. Consequently, HeLa cells were chosen to simulate an in vivo environment to investigate the intracellular antioxidant activities of the LEO and its inclusion complexes with the concentration of $0.1 \mu \mathrm{L} / \mathrm{mL}$, which was within the non-cytotoxic range $(<0.2 \mu \mathrm{L} / \mathrm{mL})$. In the living cells, non-fluorescent DCFH-DA could be hydrolyzed by esterases with the production of 2',7'-dichlorodihydrofluorescein (DCFH) [Labieniec \& Gabryelak, 2007]. The non-fluorescent DCFH are then oxidized to fluorescent product 2',7'-dichlorofluorescein (DCF) by reactive oxygen species (ROS), which could be induced by $\mathrm{H}_{2} \mathrm{O}_{2}$. The fluorescent intensity of DCF correlates with the cellular ROS content, and this intensity decreases with the presence of antioxidants due to their ability to scavenge free radicals [Qian et al., 2012; Xu \& Chang, 2012].

Figure $5 \mathrm{~A}$ shows the integral areas of relative fluorescence intensity of HeLa cells (control) and HeLa cells with LEO and microcapsules of LEO/ $\beta-\mathrm{CD}$ and $\mathrm{LEO} / \mathrm{K}-\beta \mathrm{CD}-\mathrm{MOF}$. After 1- $\mathrm{h} \mathrm{H}_{2} \mathrm{O}_{2}$ stimulation, the intensity in the control was about 8 times as that of the blank without $\mathrm{H}_{2} \mathrm{O}_{2}$ stimulation. The relative fluorescence intensities of cells with LEO, LEO/ $\beta-\mathrm{CD}$ and $\mathrm{LEO} / \mathrm{K}-\beta \mathrm{CD}-\mathrm{MOF}$ were all significantly lower than the control, indicating that both LEO and its inclusion complexes showed significant intracellular ROS scavenging activity in HeLa cells. The intracellular antioxidant activity (CAA) of LEO and its inclusion complexes were also shown in Figure $5 \mathrm{~B}$. LEO/K- $\beta \mathrm{CD}$-MOFs showed significantly higher
CAA than LEO. The lavender essential oil has been reported with high contents of oxygenated monoterpenes $(31.53 \%)$ and monoterpene hydrocarbons (8.03\%) [Dong et al., 2020]. For example, linalool - which is the major oxygenated monoterpene of lavender - accounts for $19.71 \%$ of its essential oil [Dong et al., 2020]. The essential oils rich in monoterpenes and oxygenated monoterpenes generally show a high antioxidative potential [Deba et al., 2008; Tepe et al., 2004]. Monoterpenes are very active due to the presence of a double bond between two carbon atoms $(\mathrm{C}=\mathrm{C})$, and thus they could act as free radical scavengers [Mercier et al., 2009]. Therefore, lavender essential oil played a role in scavenging intracellular ROS, leading to the high CAA of LEO and its microencapsulated products.

The higher scavenging ability of LEO/K- $\beta C D-M O F s$ is due to the higher solubility and availability in the cells compared to LEO and $\mathrm{LEO} / \beta-\mathrm{CD}$, which is in agreement with the reported higher solubility of $\mathrm{K}-\beta \mathrm{CD}-\mathrm{MOF}$ s than $\beta-\mathrm{CD}$ [Han et al., 2018]. Another possible reason might be the different microencapsulation capabilities of K- $\beta C D-M O F s$ for different guest molecules. Yuan et al. [2019] reported that the microencapsulation by HPCD could change the relative contents of the major components of LEO dramatically. For example, contents of linalyl anthranilate and linalool changed from $42.18 \%$ to $24.05 \%$ and $34.94 \%$ to $60.87 \%$, respectively, i.e., they found that hydrocarbons and esters decreased, while conversely, carbonyl compounds and alcohols increased. Alcohols and carbonyl compounds were easier encapsulated by HPCD than other compounds of LEO. This phenomenon might be attributed to the properties of the hydrophobic cavity of HPCD [Yuan et al., 2019]. The similar explanation might apply to the present study. Therefore, future study should be carried on to analyze the LEO composition before and after microencapsulation by $\mathrm{K}-\beta \mathrm{CD}-\mathrm{MOF}$, and also to compare antioxidant activities among different compounds in LEO. 

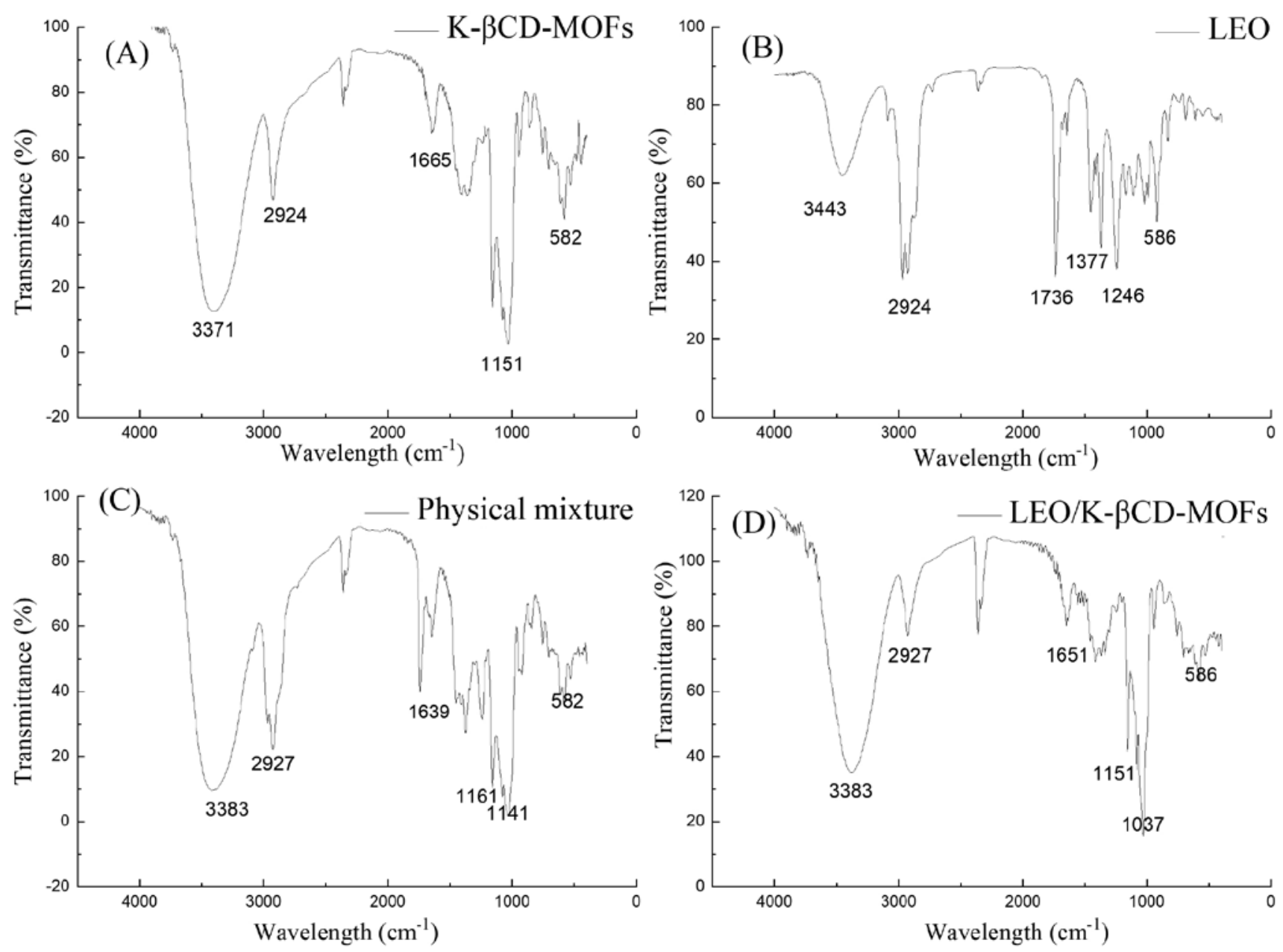

FIGURE 6. Infrared spectra of metal-organic frameworks based on $\beta$-cyclodextrin and potassium cation (K- $\beta$ CD-MOFs) (A), lavender essential oil (LEO) (B), physical mixture of LEO and $\mathrm{K}-\beta \mathrm{CD}-\mathrm{MOF}(\mathrm{C})$, and LEO/K- $\beta \mathrm{CD}-\mathrm{MOF}$ inclusion complex (D).

The LEO/ $\beta-\mathrm{CD}$ and $\mathrm{LEO} / \mathrm{K}-\beta \mathrm{CD}-\mathrm{MOF}$ inclusion complexes with core/wall ratio of 1:10 were used.

Wu et al. [2019] synthesized porous Zn@MOF and used it for microencapsulation of thymol for pathogen inhibition, and the T-Zn@MOF was proved to effectively inhibit E. coli. The present study was successful in synthesizing edible MOFs using $\beta-\mathrm{CD}$ and potassium ion. It is hopeful that $\mathrm{K}-\beta \mathrm{CD}-\mathrm{MOF}$ could be applied to the applications of LEO with improved antioxidant activities in the food industries in the near future.

\section{Characterization of LEO, LEO/ $/$-CD and LEO/K- $\beta C D$ - -MOFs}

Fourier transform infrared spectroscopy (FTIR)

The Fourier transform infrared spectroscopy technology is usually helpful in detecting the interaction between cyclodextrin or MOFs as host and the guest molecules [Liu et al., 2019; Tu et al., 2020; Yuan et al., 2019]. The inclusion complexes could be confirmed by FTIR with the variation of position, intensity and even the shape of the peaks [Yuan et al., 2019]. Yuan et al. [2019] employed FTIR to provide the solid evidence for the formation of inclusion compounds of LEO by HPCD. Tu et al. [2020] also applied FTIR to support the formation of an inclusion complex of Mxene/carbon nanohorn with K- $\beta C D-M O F s$. FTIR was also applied to demonstrate the formation of inclusion complex in the present study. The infrared spectra of the K- $\beta C D-M O F s, ~ L E O$, the physical mixture of LEO and K- $\beta C D-M O F s$, as well as $L E O / K-\beta C D-$ -MOFs inclusion complex were shown in Figure 6. Because the inclusion complexes were cleaned with petroleum ether 3 times, it could be considered that no LEO existed on the surface of the inclusion complex. If the absorption peak of the functional group of LEO could be found in the infrared absorption spectrogram of the inclusion complexes, we can deduce that LEO has been encapsulated by K- $\beta C D-M O F s$.

The spectrum of K- $\beta C D$-MOFs (Figure $6 \mathrm{~A}$ ) showed the characteristic absorption peaks of $\beta-\mathrm{CD}$, suggesting the synthetic K- $\beta C D$-MOFs based on $\beta$-CD still kept the cavity structure of $\beta-\mathrm{CD}$. The absorption peak between $3300-3400 \mathrm{~cm}^{-1}$ belongs to $-\mathrm{OH}$, and the characteristic peak of $-\mathrm{CH}_{2}$ is at $2924 \mathrm{~cm}^{-1}$. The peaks around $1151 \mathrm{~cm}^{-1}$ represent the $\mathrm{C}-\mathrm{O}$ stretching vibration absorption peak of K- $\beta \mathrm{CD}-\mathrm{MOF}$ and the inner cavity of the inclusion complexes.

Figure 6B showed the LEO infrared spectrum with the characteristic absorption peak of $\mathrm{C}=\mathrm{O}$ at $1651 \mathrm{~cm}^{-1}$. The spec- 


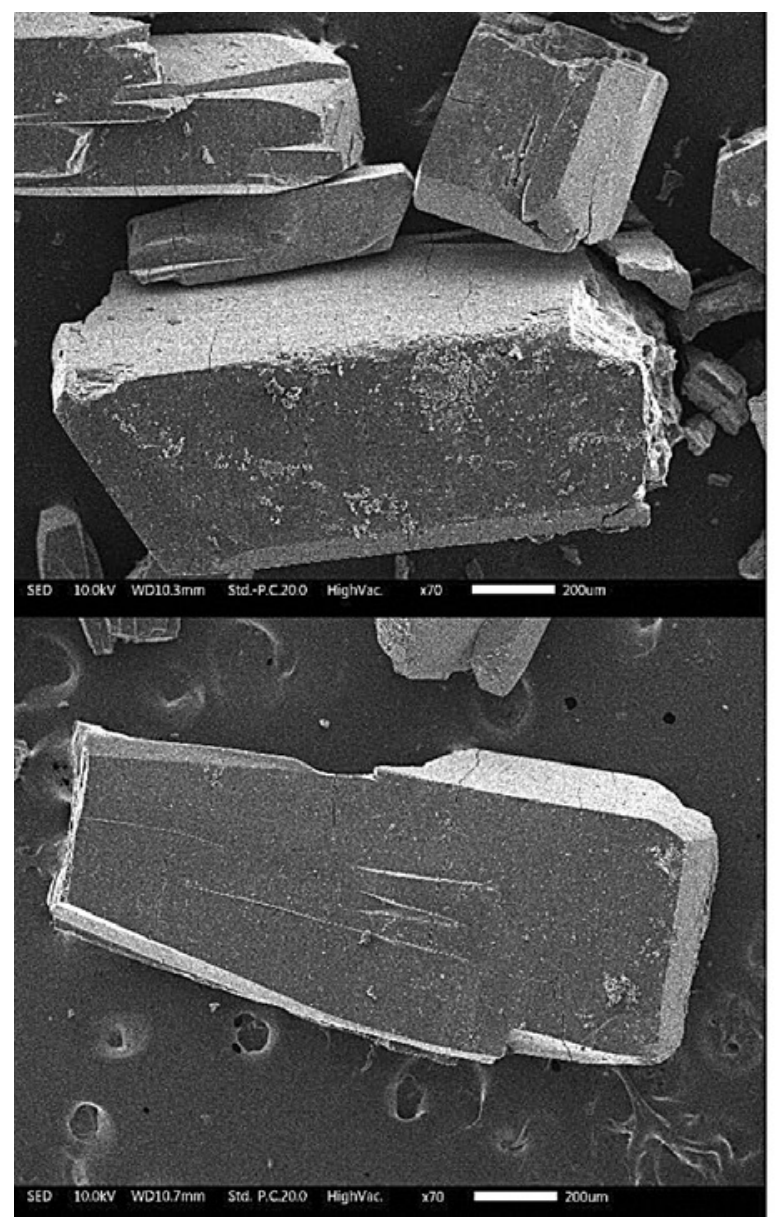

B-CD-MOFs

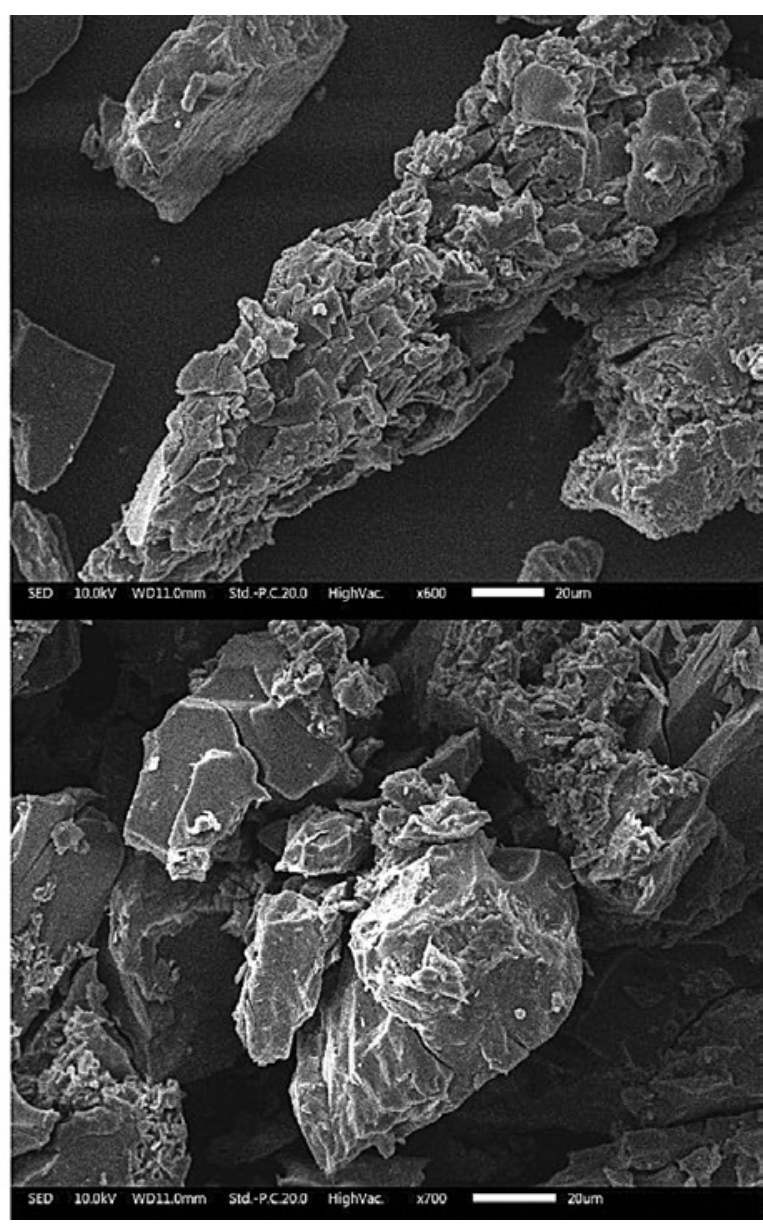

LEO/K-ßCD-MOFs

FIGURE 7. Scanning electron microscope pictures of metal-organic frameworks based on $\beta$-cyclodextrin and potassium cation (K- $\beta \mathrm{CD}-\mathrm{MOFs}$ ) and lavender essential oil (LEO)/K- $\beta C D$-MOFs inclusion complex.

The LEO/K- $\beta$ CD-MOFs inclusion complexes with core/wall ratio of 1:10 were used. The magnifications are 70 and 700 times, respectively.

tra of the physical mixture and the inclusion complex were presented in Figure 6C, D, respectively. The main absorption peaks $\left(-\mathrm{OH}, \mathrm{C}=\mathrm{O}, \mathrm{C}-\mathrm{O},-\mathrm{CH}_{3}\right.$ and $\left.-\mathrm{CH}_{2}\right)$ of the two substances were generally similar to those of $\mathrm{K}-\beta \mathrm{CD}-\mathrm{MOF}$. As the mass core/wall ratio was 1:10, the amounts of K- $\beta C D-M O F$ s in both substances were much larger than that of LEO, resulting in the embedment of the LEO peaks in the bulk K- $\beta C D$-MOFs matrix. As the microencapsulation of LEO by K- $\beta C D-M O F s$ was probably due to van der Waals force [Li et al., 2017], the absorption frequency and peak shape in the infrared spectra of the functional groups did not change after the microencapsulation. However, the peak intensities of the inclusion complexes were different from those of K- $\beta C D-M O F s$ and LEO. This could be explained by the fact that LEO was bound and affected by the van der Waals force, which might cause the hinderance of its vibration and finally lead to the changes of intensity or even the disappearance of the peaks.

Finally, the spectrum of the inclusion compounds was obviously different from that of the physical mixture, especially regarding the $\mathrm{C}=\mathrm{O}$ stretching vibration peak (around $1651 \mathrm{~cm}^{-1}$ ) of LEO. This indicated that the LEO's environment in the inclusion compounds was different from that in the physical mixture. The weakening and the disappearance of some absorp- tion peaks suggested that LEO has been successfully loaded as some groups have entered the cavity of $\mathrm{CD}$. All the above infrared results proved the formation of $\mathrm{LEO} / \mathrm{K}-\beta \mathrm{CD}-\mathrm{MOF}$.

\section{Scanning electron microscope (SEM)}

SEM has been commonly used to characterize the morphology and crystal structures of different MOFs [Wu et al., 2019]. To further characterize the inclusion complexes, the microstructures of K- $\beta C D-M O F s$ and $\mathrm{LEO} / \mathrm{K}-\beta \mathrm{CD}-\mathrm{MOF}$ were observed by SEM. First, the representative SEM images of K- $\beta C D-M O F s$ were shown in Figure 7 . The crystalline $\mathrm{K}-\beta \mathrm{CD}-\mathrm{MOF}$ has a long cuboid morphology, which is consistent with other researches [Liu et al., 2019; Tu et al., 2010]. The present study and the previous researches indicated K- $\beta C D$-MOFs were a rectangular solid with various sizes from millimeter to micron. For instance, Liu et al. [2019] showed the size of K- $\beta C D$-MOFs varied from $500 \mathrm{~nm}$ to 2 or several millimeters once examined by transmission electron microscope (TEM) and SEM. Figure 1 shows the size of $\mathrm{K}-\beta \mathrm{CD}-\mathrm{MOF}$ was around several millimeters. Besides, by comparison with Figure $7, \mathrm{~K}-\beta \mathrm{CD}-\mathrm{MOF}$ could be deemed smooth and long cubic crystals, while LEO/K- $\beta$ CD-MOFs exhibited a relatively rough surface, which is a new image. 

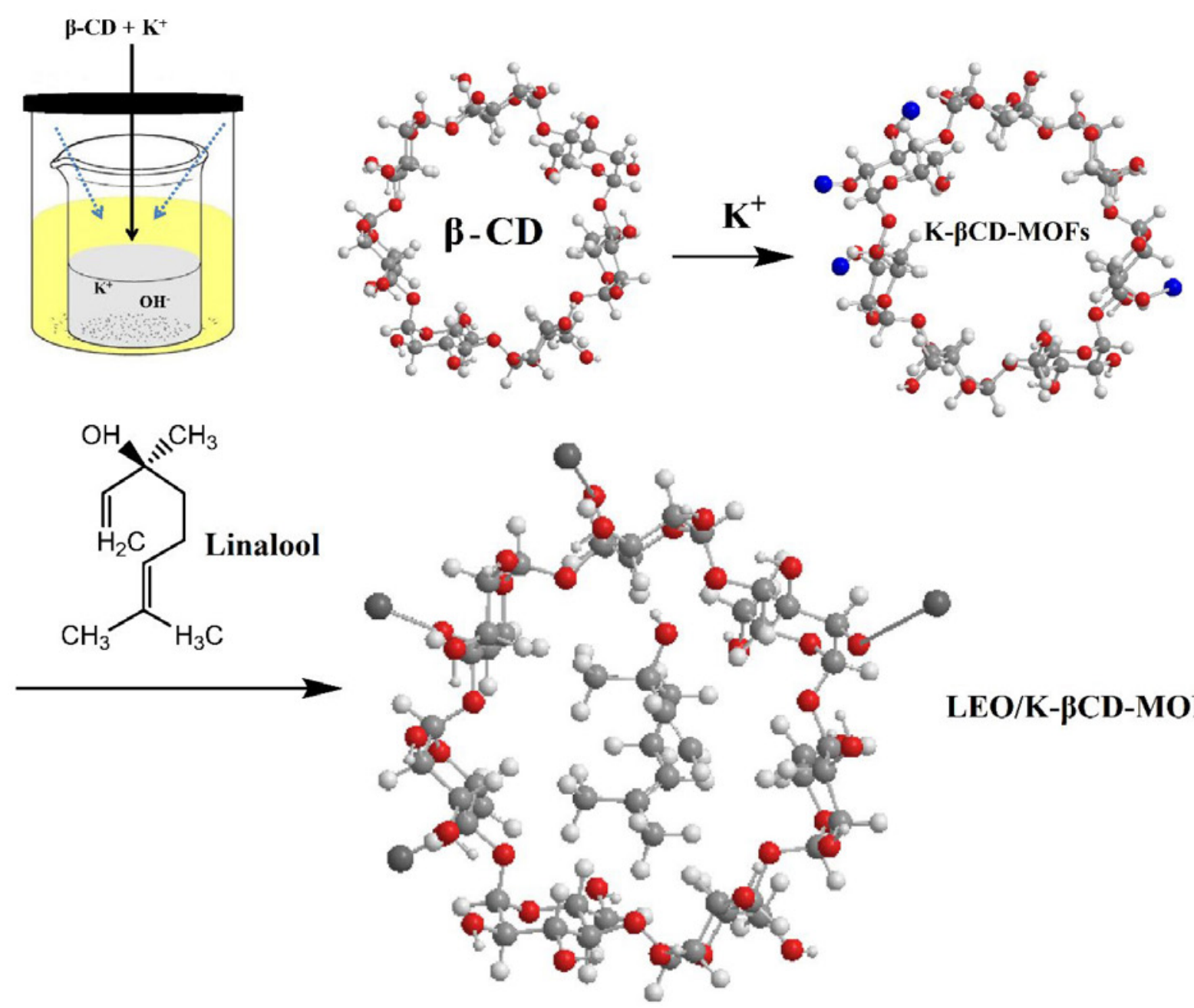

LEO/K-ßCD-MOFs

FIGURE 8. The scheme for the possible microencapsulation mechanism of lavender essential oil (LEO) by metal-organic frameworks based on $\beta$-cyclodextrin and potassium cation (K- $\beta \mathrm{CD}-\mathrm{MOFs}$ ) as the inclusion materials.

Linalool as the main component of LEO was taken as an example.

\section{Possible mechanism of the production of $\mathrm{LEO} / \mathrm{K}-\beta \mathrm{CD}$ - -MOFs microcapsule}

The formation of K- $\beta C D$-MOFs was plotted in Figure 8. The potassium ion $\left(\mathrm{K}^{+}\right)$is paired with seven oxygen atoms (O) of the four surrounding $\beta-\mathrm{CD}$ [Lu et al., 2015]. On the other hand, to further deduce the microencapsulation mechanism of the production of LEO/K- $\beta C D-M O F s$ microcapsule, linalool is taken as an example as it is the main component of LEO [Dong et al., 2020]. The optimum mass core/wall ratio of linalool to K- $\beta C D-M O F s$ at $1: 10$ is equaled to the molar ratio of about $1: 1$. The scheme for the possible microcapsule formation is shown in Figure 8. In detail, when linalool was encapsulated by K- $\beta \mathrm{CD}-\mathrm{MOF}$, one $\mathrm{K}-\beta \mathrm{CD}-\mathrm{MOF}$ molecules could encapsulate one linalool molecule (Figure 8). The specific reaction mechanism of the microencapsulation between LEO and K- $\beta C D$-MOFs deserves further research by single crystal X-ray diffraction, elemental analysis, and so forth.

\section{CONCLUSIONS}

Studies on the microencapsulation of lavender essential oil by $\beta-C D$ and K- $\beta C D-M O F s$ as well as analyses of the sta- bility and antioxidant activity in HeLa cells of the LEO/ $\beta-\mathrm{CD}$ and $\mathrm{LEO} / \mathrm{K}-\beta \mathrm{CD}-\mathrm{MOF}$ inclusion complexes were carried out. Our results showed the formation of a complex between LEO and CD-MOFs, as evidenced by FTIR and SEM. Furthermore, the microcapsules of $\mathrm{LEO} / \mathrm{K}-\beta \mathrm{CD}-\mathrm{MOF}$ were proved to be more thermally and acid-base stable than LEO, and its intracellular antioxidant effect was also significantly improved by encapsulation. The microencapsulation of LEO by K- $\beta C D-M O F s$ not only did not inhibit the intracellular antioxidant activities of LEO, but also significantly improved their ROS scavenging abilities. All these indicated the application of lavender essential oil to food and medicine would be expanded, as the new functional K- $\beta C D$-MOFs materials prepared based on $\beta-C D$ have great benefits to future. This information provides solid evidence and foundation for the future applications of LEO, and thus improves the production of tailor-made commodities by addressing different requirements of manufacturers of this herbal plant as medicines, herbal teas, food seasoning, cosmetics, and etc. The advantages of K- $\beta C D$-MOFs make them not only limited to chemical industry, but also applicable to new fields including foods, pharmaceuticals or health care products, etc. 


\section{RESEARCH FUNDING}

The present work was supported by the Natural Science Foundation of Tianjin (grant numbers 17JCQNJC02400 and 18JCYBJC96000), the National Training Programs for Innovation and Entrepreneurship of Undergraduates (grant number 201910069019), 131 Second Level Innovative Talents Training Project in Tianjin, and Young and Middle-aged Key Innovative Talents Training Project of Tianjin Universities.

\section{CONFLICT OF INTEREST}

Authors declare no conflict of interest

\section{ORCID IDs}

J. Tan http://orcid.org/0000-0002-3515-7804

Y. Wang https://orcid.org/0000-0002-4933-9158

\section{REFERENCES}

1. Abuçafy, M.P., Caetano, B.L., Chiari-Andréo, B.G., Fonseca-Santos, B., do Santos, A.M., Chorilli, M., Chiavacci, L.A. (2018). Supramolecular cyclodextrin-based metal-organic frameworks as efficient carrier for anti-inflammatory drugs. European Journal of Pharmaceutics and Biopharmaceutics, 127, 112-119. https://doi.org/10.1016/j.ejpb.2018.02.009

2. Adach, K., Fijalkowski, M., Gajek, G., Skolimowski, J., Kontek, R., Blaszczyk, A. (2016). Studies on the cytotoxicity of diamond nanoparticles against human cancer cells and lymphocytes. Chemico-biological Interactions, 254, 156-166.

https://doi.org/10.1016/j.cbi.2016.06.004

3. Bensouda, Z., Sfaira, M., Touhami, M.E., Farah, A., Hammouti, B. (2019). Extraction, characterization and anticorrosion potential of an essential oil from orange zest as eco-friendly inhibitor for mild steel in acidic solution. Journal of Bio-and Tribo-Corrosion, $5(4), 84$. https://doi.org/10.1007/s40735-019-0276-y

4. Cavanagh, H.M., Wilkinson, J.M. (2005). Lavender essential oil: A review. Australian Infection Control, 10(1), 35-37. https://doi.org/10.1071/HI05035

5. Deba, F., Xuan, T.D., Yasuda, M., Tawata, S. (2008). Chemical composition and antioxidant, antibacterial and antifungal activities of the essential oils from Bidens pilosa Linn. var. Radiata. Food Control, 19(4), 346-352.

https://doi.org/10.1016/j.foodcont.2007.04.011

6. Deng, S., Liu, H., Qi, C., Yang, A., Li, Z. (2018). Study on preparation and inclusion behavior of inclusion complexes between $\beta$-cyclodextrin derivatives with benzophenone. Journal of Inclusion Phenomena and Macrocyclic Chemistry, 90(3-4), 321-329. https://doi.org/10.1007/s10847-018-0787-z

7. Dong, G., Bai, X., Aimila, A., Aisa, H.A., Maiwulanjiang, M. (2020). Study on lavender essential oil chemical compositions by GC-MS and improved pGC. Molecules, 25(14), 3166.

https://doi.org/10.3390/molecules25143166

8. Gezici, S. (2018). Promising anticancer activity of lavender (Lavandula angustifolia Mill.) essential oil through induction of both apoptosis and necrosis. Annals of Phytomedicine, 7(2), 38-45. https://doi.org/10.21276/ap.2018.7.2.5
9. Han, Y., Liu, W., Huang, J., Qiu, S., Zhong, H., Liu, D., Liu, J. (2018). Cyclodextrin-based metal-organic frameworks (CD-MOFs) in pharmaceutics and biomedicine. Pharmaceutics, 10(4), 271. https://doi.org/10.3390/pharmaceutics10040271

10. Insawang, S., Pripdeevech, P., Tanapichatsakul, C., Khruengsai, S., Monggoot, S., Nakham, T., Artrod, A., D’Souza, P.E., Panuwet, P. (2019). Essential oil compositions and antibacterial and antioxidant activities of five Lavandula stoechas cultivars grown in Thailand. Chemistry \& Biodiversity, 16(10), e1900371. https://doi.org/10.1002/cbdv.201900371

11. Kumar, S., Jain, S., Nehra, M., Dilbaghi, N., Marrazza, G., Kim, K.H. (2020). Green synthesis of metal-organic frameworks: A state-of-the-art review of potential environmental and medical applications. Coordination Chemistry Reviews, 420, 213407. https://doi.org/10.1016/j.ccr.2020.213407

12. Kwiatkowski, P., Łopusiewicz, Ł., Kostek, M., Drozłowska, E., Pruss, A., Wojciuk, B., Sienkiewicz, M., Zielińska-Bliźniewska, H., Dołęgowska, B. (2020). The antibacterial activity of lavender essential oil alone and in combination with octenidine dihydrochloride against MRSA strains. Molecules, 25(1), 95. https://doi.org/10.3390/molecules25010095

13. Labieniec, M., Gabryelak, T. (2007). Antioxidative and oxidative changes in the digestive gland cells of freshwater mussels Unio tumidus caused by selected phenolic compounds in the presence of $\mathrm{H}_{2} \mathrm{O}_{2}$ or $\mathrm{Cu}^{2+}$ ions. Toxicology in Vitro, 21(1), 146-156. https://doi.org/10.1016/j.tiv.2006.09.017

14. Li, S., Huo, F. (2015). Metal-organic framework composites: from fundamentals to applications. Nanoscale, 7(17), 7482-7501. https://doi.org/10.1039/C5NR00518C

15. Li, X., Guo, T., Lachmanski, L., Manoli, F., Menendez-Miranda, M., Manet, I., Guo, Z., Wu, L., Zhang, J.W., Gref, R. (2017). Cyclodextrin-based metal-organic frameworks particles as efficient carriers for lansoprazole: study of morphology and chemical composition of individual particles. International Journal of Pharmaceutics, 531(2), 424-432.

https://doi.org/10.1016/j.ijpharm.2017.05.056

16. Lis-Balchin, M. (2002). Lavender: The Genus Lavandula. (Medicinal and Aromatic Plants - Industrial Profiles). $1^{\text {st }}$ ed., Taylor \& Francis, London, UK, p. 86, p. 100. https://doi.org/10.1201/9780203216521

17. Liston, B.W., Nines, R., Carlton, P.S., Gupta, A., Aziz, R., Frankel, W., Stoner, G.D. (2003). Perillyl alcohol as a chemopreventive agent in N-nitrosomethylbenzylamine-induced rat esophageal tumorigenesis. Cancer Research, 63(10), 2399-2403.

18. Liu, C., Wang, P., Liu, X., Yi, X., Zhou, Z., Liu, D. (2019). Multifunctional $\beta$-cyclodextrin MOF-derived porous carbon as efficient herbicides adsorbent and potassium fertilizer. ACS Sustainable Chemistry \& Engineering, 7(17), 14479-14489. https://doi.org/10.1021/acssuschemeng.9b01911

19. Liu, J., Bao, T.Y., Yang, X.Y., Zhu, P.P., Wu, L.H., Sha, J.Q., Zhang, L., Dong, L.Z., Cao, X.L., Lan, Y.Q. (2017). Controllable porosity conversion of metal-organic frameworks composed of natural ingredients for drug delivery. Chemical Communications, 53(55), 7804-7807. https://doi.org/10.1039/C7CC03673F

20. Lu, H.J., Yang, X.N., Sha, J.Q., Li, C.D., Li, X.T. (2015). Synthesis and $\mathrm{AM}$ inclusion technology of $\beta$-CD-metal organic framework. Journal of Harbin University of Science and Technology, 20(4), 35-40 (in Chinese; English abstract). 
21. Lv, N., Guo, T., Liu, B., Wang, C., Singh, V., Xu, X., Li, X., Chen, D., Gref, R., Zhang, J. (2017). Improvement in thermal stability of sucralose by $\gamma$-cyclodextrin metal-organic frameworks. Pharmaceutical Research, 34(2), 269-278. https://doi.org/10.1007/s11095-016-2059-1

22. Mercier, B., Prost, J., Prost, M. (2009). The essential oil of turpentine and its major volatile fraction ( $\alpha$-and $\beta$-pinenes): A review. International Journal of Occupational Medicine and Environmental Health, 22(4), 331-342.

https://doi.org/10.2478/v10001-009-0032-5

23. Michida, W., Ezaki, M., Sakuragi, M., Guan, G., Kusakabe, K. (2015). Crystal growth of cyclodextrin-based metal-organic framework with inclusion of ferulic acid. Crystal Research and Technology, 50(7), 556-559.

\section{https://doi.org/10.1002/crat.201500053}

24. Partanen, R., Ahro, M., Hakala, M., Kallio, H., Forssell, P. (2002). Microencapsulation of caraway extract in $\beta$-cyclodextrin and modified starches. European Food Research and Technology, 214(3), 242-247.

https://doi.org/10.1007/s00217-001-0446-1

25. Qian, Z.J., Kang, K.H., Kim, S.K. (2012). Isolation and antioxidant activity evaluation of two new phthalate derivatives from seahorse, Hippocampus kuda Bleeler. Biotechnology and Bioprocess Engineering, 17(5), 1031-1040.

https://doi.org/10.1007/s12257-012-0115-1

26. Samaila, D., Ezekwudo, D.E., Yimam, K.K., Elegbede, J.A. (2004). Bioactive plant compounds inhibited the proliferation and induced apoptosis in human cancer cell lines, in vitro. In Transactions of the Integrated Bio-Medical Informatics \& Enabling Technologies Symposiums, 1, 34-42.

27. Shafaei, S.M., Nourmohamadi-Moghadami, A., Kamgar, S. (2017). Experimental analysis and modeling of frictional behavior of lavender flowers (Lavandula stoechas L.). Journal of Applied Research on Medicinal and Aromatic Plants, 4, 5-11. https://doi.org/10.1016/j.jarmap.2016.07.001

28. Smaldone, R.A., Forgan, R.S., Furukawa, H., Gassensmith, J.J., Slawin, A.M., Yaghi, O.M., Stoddart, J.F. (2010). Metal-organic frameworks from edible natural products. Angewandte Chemie International Edition, 49(46), 8630-8634. https://doi.org/10.1002/anie.201002343

29. Tepe, B., Donmez, E., Unlu, M., Candan, F., Daferera, D., Vardar-Unlu, G., Sokmen, A. (2004). Antimicrobial and antioxidative activities of the essential oils and methanol extracts of Salvia cryptantha (Montbret et Aucher ex Benth.) and Salvia multicaulis (Vahl). Food Chemistry, 84(4), 519-525.

https://doi.org/10.1016/S0308-8146(03)00267-X

30. Thombre, R.S., Kanekar, P.P., Rajwade, J.M. (2013). Production of cyclodextrin glycosyltransferase from alkaliphilic Paenibacillus $s p$ L55 MCM B-1034 isolated from alkaline lonar lake, India. International Journal of Pharma Bioscience and Technology, 4(1), 515-523.

31. Tian, B., Hua, S., Liu, J. (2020). Cyclodextrin-based delivery systems for chemotherapeutic anticancer drugs: A review. Carbohydrate Polymers, 232, 115805. https://doi.org/10.1016/j.carbpol.2019.115805

32. Tu, X., Gao, F., Ma, X., Zou, J., Yu, Y., Li, M., Qu, F., Huang, X., Lu, L. (2020). Mxene/carbon nanohorn/ $\beta$-cyclodextrin-Metalorganic frameworks as high-performance electrochemical sens- ing platform for sensitive detection of carbendazim pesticide. Journal of Hazardous Materials, 122776.

https://doi.org/10.1016/j.jhazmat.2020.122776

33. Usta, J., Kreydiyyeh, S., Knio, K., Barnabe, P., Bou-Moughlabay, Y., Dagher, S. (2009). Linalool decreases HepG2 viability by inhibiting mitochondrial complexes I and II, increasing reactive oxygen species and decreasing ATP and GSH levels. ChemicoBiological Interactions, 180(1), 39-46.

https://doi.org/10.1016/j.cbi.2009.02.012

34. Wang, Y., Jiang, Z.T., Li, R. (2009). Complexation and molecular microcapsules of Litsea cubeba essential oil with $\beta$-cyclodextrin and its derivatives. European Food Research and Technology, 228(6), 865-873.

https://doi.org/10.1007/s00217-008-0999-3

35. Wang, Y., Li, R., Jiang, Z.T., Tan, J., Tang, S.H., Li, T.T., Liang, L.L., He, H.J., Liu, Y.M., Li, J.T., Zhang, X.C. (2018). Green and solvent-free simultaneous ultrasonic-microwave assisted extraction of essential oil from white and black peppers. Industrial Crops and Products, 114, 164-172.

https://doi.org/10.1016/j.indcrop.2018.02.002

36. Wang, Y., Liu, T., Li, M.F., Yang, Y.S., Li, R., Tan, J., Tang, S.H., Jiang, Z.T. (2019). Composition, cytotoxicity and antioxidant activities of polyphenols in the leaves of star anise (Illicium verum Hook. f.). ScienceAsia, 45(6), 532-537.

https://doi.org/10.2306/scienceasia1513-1874.2019.45.532

37. Wu, Y., Luo, Y., Zhou, B., Mei, L., Wang, Q., Zhang, B. (2019). Porous metal-organic framework (MOF) carrier for incorporation of volatile antimicrobial essential oil. Food Control, 98, 174-178.

https://doi.org/10.1016/j.foodcont.2018.11.011

38. Xu, B., Chang, S.K. (2012). Comparative study on antiproliferation properties and cellular antioxidant activities of commonly consumed food legumes against nine human cancer cell lines. Food Chemistry, 134(3), 1287-1296. https://doi.org/10.1016/j.foodchem.2012.02.212

39. Yang, L.C., Li, R., Tan, J., Jiang, Z.T. (2013). Polyphenolics composition of the leaves of Zanthoxylum bungeanum Maxim. grown in Hebei, China, and their radical scavenging activities. Journal of Agricultural and Food Chemistry, 61 (8), 1772-1778. https://doi.org/10.1021/jf3042825

40. Young, L., Sung, J., Stacey, G., Masters, J.R. (2010). Detection of mycoplasma in cell cultures. Nature Protocol, 5(5), 929. https://doi.org/10.1038/nprot.2010.43

41. Yuan, C., Wang, Y., Liu, Y., Cui, B. (2019). Physicochemical characterization and antibacterial activity assessment of lavender essential oil encapsulated in hydroxypropyl-beta-cyclodextrin. Industrial Crops and Products, 130, 104-110. https://doi.org/10.1016/j.indcrop.2018.12.067

42. Zhao, Y., Chen, R., Wang, Y., Qing, C., Wang, W., Yang, Y. (2017). In vitro and in vivo efficacy studies of Lavender angustifolia essential oil and its active constituents on the proliferation of human prostate cancer. Integrative Cancer Therapies, 16(2), 215-226. https://doi.org/10.1177/1534735416645408

Submitted: 5 October 2020. Revised: 21 December 2020. Accepted: 31 December 2020. Published on-line: 25 January 2021. 